\title{
Notas e descrições em Eburiini (Coleoptera, Cerambycidae)
}

\author{
Maria Helena M. Galileo ${ }^{1,3}$ \& Ubirajara R. Martins ${ }^{2,3}$ \\ 1. Museu de Ciências Naturais, Fundação Zoobotânica do Rio Grande do Sul, Caixa Postal 1188, 90001-970 Porto Alegre, RS, Brasil. \\ 2. Museu de Zoologia, Universidade de São Paulo, Caixa Postal 42494, 04218-970 São Paulo, SP, Brasil. \\ 3. Pesquisador do CNPq.
}

\begin{abstract}
Notes and descriptions in Eburiini (Coleoptera, Cerambycidae). New taxa described: Neoeburia gen. nov., type species N. turuna sp. nov., from Peru (Lima); Eburodacrys silviamariae sp. nov., from Peru (Cuzco); E. putia sp. nov., from Bolivia (Santa Cruz); E. ayri sp. nov., from Colombia; E. aenigma sp. nov., procedence unknown. New records: Eburella pinima Martins, 1967, Peru (Huanuco); Beraba piriana Martins, 1997, Panama (Panama); Eburodacrys campestris Gounelle, 1909, Bolivia (Santa Cruz).
\end{abstract}

KEYWORDS. Cerambycinae, Eburodacrys, Neoeburia, Neotropical, taxonomy.

RESUMO. Notas e descrições em Eburiini (Coleoptera, Cerambycidae). Novos táxons descritos: Neoeburia gen. nov., espécie-tipo N. turuna sp. nov., do Peru (Lima); Eburodacrys silviamariae sp. nov., do Peru (Cuzco); E. putia sp. nov., da Bolívia (Santa Cruz); E. ayri sp. nov., da Colômbia; E. aenigma sp. nov., procedência desconhecida. Novos registros: Eburella pinima Martins, 1967, Peru (Huanuco); Beraba piriana Martins, 1997, Panamá (Panamá); Eburodacrys campestris Gounelle, 1909, Bolívia (Santa Cruz).

PALAVRAS-CHAVE. Cerambycinae, Eburodacrys, Neoeburia, Neotropical, taxonomia.

A tribo Eburiini foi recentemente revista (MARTINS, 1999) e chaves atualizadas e novas espécies foram acrescentadas por GALILEO \& MARTINS (2004) e MARTINS \& Galileo $(2002,2005 a, b)$. Pelo recente catálogo de Monné (2005), a tribo conta com 229 espécies na Região Neotropical.

O material estudado pertence ao National Museum of Natural History, Washington (USNM), representado por espécimes da ex-coleção F. Tippmann, recebidos por especial deferência de James E. Wappes que ainda determinou que os holótipos das espécies bolivianas da sua coleção (ACMB) fossem depositados no Museu Noel Kempf Mercado, Santa Cruz, Bolívia (MNKM). Algumas duplicatas foram retidas para o Museu de Zoologia, Universidade de São Paulo, São Paulo (MZSP).

\section{Neoeburia gen. nov.}

Espécie-tipo, Neoeburia turuna sp. nov.

Vértice sem tubérculo. Olhos grosseiramente granulados. Tubérculos anteníferos não-projetados. Genas com ápice arredondado; ápice (40x) com a borda elevada. Gula sem sulcos transversais. Antenas com onze artículos; nos machos, apenas mais curtas que o corpo. Escapo subcilíndrico, sem sulco no lado dorsal da base; comprimento maior que a metade do antenômero III. Antenômero III sem sulcos ou carenas. Protórax tão largo quanto longo. Pronoto com dois tubérculos láteroanteriores, arredondados no topo. Partes laterais do protórax com tubérculo central de ponta arredondada e pequena projeção látero-anterior, deslocada para o dorso. Mesosterno sem tubérculo. Extremidades elitrais truncadas; ângulo sutural com espículo ou inerme. Base da epipleura sem dentículo. Ápices dos meso- e metafêmures com espinho interno. Urosternitos dos machos sem áreas pubescentes.

Discussão. Pela chave para os gêneros de Eburiini publicada por MARTINS (1999:128), Neoeburia gen. nov. é discriminado no item 12, junto com Beraba Martins, 1997 e Quiacaua Martins, 1997. Distingue-se de Quiacaua por não possuir tubérculo no mesosterno, pelas antenas dos machos que não ultrapassam a extremidade dos élitros e tubérculos pronotais nãoaguçados. Em Quiacaua o mesosterno tem tubérculo, as antenas dos machos têm o dobro do comprimento do corpo e os tubérculos pronotais são acuminados no topo.

Difere de Beraba pelas antenas dos machos mais curtas que o corpo, pela extremidade das genas com borda elevada; pelo tubérculo látero-anterior no protórax e pelas extremidades elitrais sem espinho. Em Beraba, as antenas dos machos são, no mínimo, um terço mais longas que o corpo, a extremidade das genas não são elevadas, não existe tubérculo látero-anterior no protórax e as extremidades dos élitros são espinhosas.

\section{Neoeburia turuna sp. nov.}

(Fig. 1)

Etimologia. Tupi, turuna = preto grande, poderoso; alusivo ao colorido dos élitros.

Cabeça vermelha; vértice com tegumento brilhante e densamente pontuado. Antenas pretas. Escapo e antenômero III pontuados. Protórax vermelho; tubérculos pronotais pretos. Pronoto densamente pontuado, os pontos finos e eqüidistantes. Élitros pretos a pretoacastanhados, cada um com uma faixa ebúrnea que se inicia na base entre o escutelo e o úmero onde é mais larga e elevada, estende-se até o terço posterior onde se 


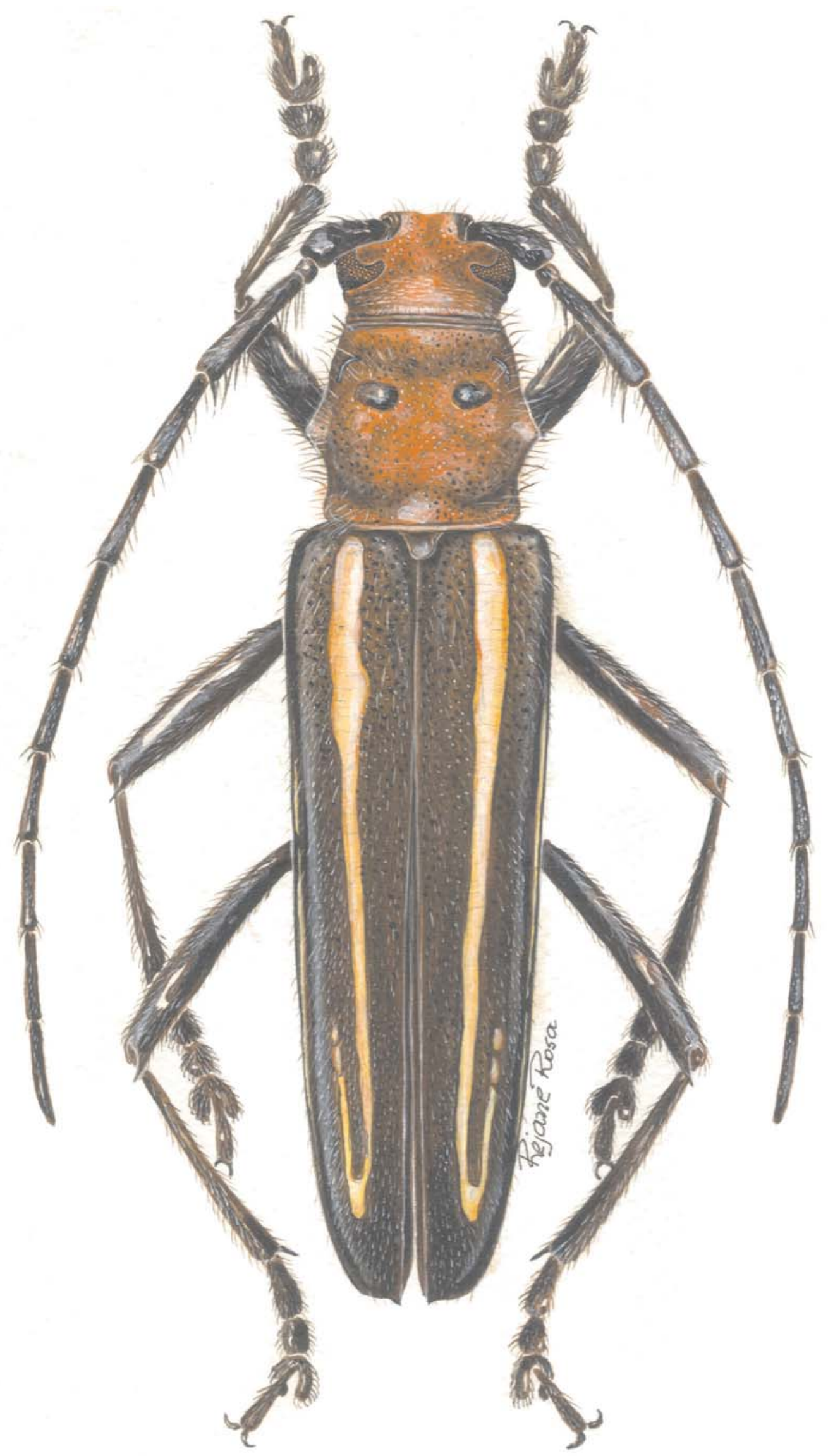

Fig.1. Neoeburia turuna sp. nov., holótipo ơ, comprimento 14,2 mm.

Iheringia, Sér. Zool., Porto Alegre, 96(2):179-184, 30 de junho de 2006 
volta para diante em ramo estreito do sexto ao terço apical (no parátipo a faixa dorsal não é contínua com o ramo); outra faixa ebúrnea, marginal, gradualmente mais estreita para o ápice, que não chega a atingir. Superfície elitral, entre as faixas ebúrneas, grosseiramente pontuada. Pernas e face ventral pretas.

Dimensões $(\mathrm{mm})$, parátipo o holótipo o respectivamente. Comprimento total, 12,9-14,2; comprimento do protórax, 2,8-3,1; maior largura do protórax, 2,8-3,2; comprimento do élitro, 9,1-10,1; largura umeral, $3,2-3,7$.

Material-tipo. Holótipo đ̊, PERU, Lima: Verrugas, 7.IV.1928, R. C. Schannon col. (USNM); parátipo ơ, mesmos dados do holótipo (MZSP).

\section{Eburella pinima Martins, 1997}

Eburella pinima MARTins, 1997:67, fig. 9; Monné, 2005:140 (cat.).

Esta espécie conhecida, até o momento, da Bolívia, registra-se agora para o Peru.

Material examinado. PERU, Huanuco: Chinchao (1.950 m), f, 18.VIII.1951, G. H. Dieke col., "on vegetation” (USNM).

\section{Beraba piriana Martins, 1997}

Beraba piriana MARTins, 1997:68, fig. 5; 1999:182; Monné, 2005:139 (cat.).

Conhecida apenas da Colômbia, Magdalena e Bolívar, assinala-se para o Panamá.

Material examinado. PANAMÁ, Panamá: El Cermeño (844'N, 7951'W), o', \&, V.1939, J. Zetek col. (USNM, MZSP).

\section{Eburodacrys campestris Gounelle, 1909}

Eburodacrys campestris Gounelle, 1909:633, fig. 19; Monné, 2005:156 (cat.).

O exemplar boliviano, ora examinado, concorda com os que apresentam manchas centrais dos élitros contíguas: a externa e a interna iniciam-se no mesmo nível. Exemplares com esse padrão foram assinalados para o Pará e o Mato Grosso, Brasil (Martins, 1999).

Material examinado. BOLÍVIA, Santa Cruz: Buena Vista, o' 18-25.X.1992, E. Giesbert col. (ACMB).

\section{Eburodacrys silviamariae sp. nov. (Fig. 2)}

Etimologia. O nome é uma homenagem à Dra. Silvia Maria Pinella Helaehil Barra, por sua dedicação e assistência médica a um dos autores (URM).

Colorido geral avermelhado. Antenas dos machos com quase o dobro do comprimento do corpo, atingem a ponta dos élitros na extremidade do antenômero VI. Escapo com sulco profundo no lado dorsal da base, sem dente basal interno. Antenômero III com sulco profundo. Protórax com espinhos laterais concolores. Pronoto com os tubérculos ântero-dorsais muito ligeiramente enegrecidos, bem projetados e arredondados no topo; entre os dois, um tubérculo bem menor; superfície pronotal com rugas irregulares grosseiras, sem pontos. Mesosterno sem tubérculo. Cada élitro com três manchas ebúrneas: uma na base, elíptica, ocupa grande área entre o escutelo e o úmero; duas centrais contíguas, curtas e largas, a externa ultrapassa a interna na frente e atrás. Metade anterior dos élitros densamente pontuada. Extremidades elitrais transversalmente truncadas, com espinhos curtos nos ângulos marginal e sutural. Espinhos femorais concolores. Tarsômeros dos machos nãointumescidos.

Dimensões (mm), holótipo . Comprimento total, 18,1; comprimento do protórax, 3,6; maior largura do protórax, 4,2; comprimento do élitro, 13,1; largura umeral, 4,9.

Material-tipo. Holótipo $ð$, PERU, Cuzco: Cosnipata (1.700 m, $\left.13^{\circ} 06^{\prime} \mathrm{S}, 71^{\circ} 18^{\prime} \mathrm{W}\right)$, XII.1951, F. Woytkowski col. (USNM).

Discussão. Eburodacrys silviamariae sp. nov. tem duas manchas ebúrneas contíguas no centro de cada élitro, a externa ultrapassando a interna anterior- e posteriormente, o que conduz, na chave para as espécies do gênero (Martins, 1999), ao item 49, onde estão discriminadas E. amazonica Melzer, 1927 e E. notula Gounelle, 1909. Eburodacrys amazonica é espécie de grandes dimensões e tem os espinhos femorais pretos.

Eburodacrys silviamariae sp. nov. distingue-se de E. notula pelos tubérculos pronotais, extremidades e espinhos femorais e perímetro das manchas dos élitros concolores; pela mancha basal dos élitros elíptica; pelo antenômero III com sulco profundo; pelos espinhos dos ápices elitrais muito curtos e pela escultura do pronoto mais grosseira. Em E. notula, os espinhos femorais, as extremidades dos fêmures e o perímetro das manchas elitrais são pretos; a mancha ebúrnea basal é mais estreita e alongada (vide Martins, 1999: 349, fig. 237); o antenômero III tem sulco raso; as extremidades dos élitros têm espinho longo e preto no lado externo e a escultura do pronoto é muito mais fina.

\section{Eburodacrys aenigma sp. nov. (Fig. 3)}

Etimologia. Latim, aenigma = obscuro, alusivo ao material sem procedência.

Colorido geral vermelho-alaranjado; pedicelo, flagelômeros, ápice dos fêmures, bases das tíbias e tarsos, pretos. Escapo alargado para o ápice, com sulco no lado superior da base. Pronoto com tubérculos anteriores concolores; superfície com rugas transversais e pontos entremeados principalmente nos lados. Tubérculo lateral do protórax com ápice escurecido. Prosterno com rugas transversais. Mesosterno com tubérculo. Cada élitro com duas faixas ebúrneas na base, a interna da base ao quarto anterior e a externa muito mais estreita e mais curta (atinge o meio da interna); duas centrais, separadas, a interna mais curta e a externa inicia-se quase no mesmo nível da interna e ultrapassa-a posteriormente em metade do seu comprimento. A parte anterior das manchas centrais, mais escurecida. Presença de mais uma faixa ebúrnea lateral, estreita, afastada da margem, que vai do terço basal ao meio. Base dos élitros densamente pontuada e espinhos apicais escurecidos. 


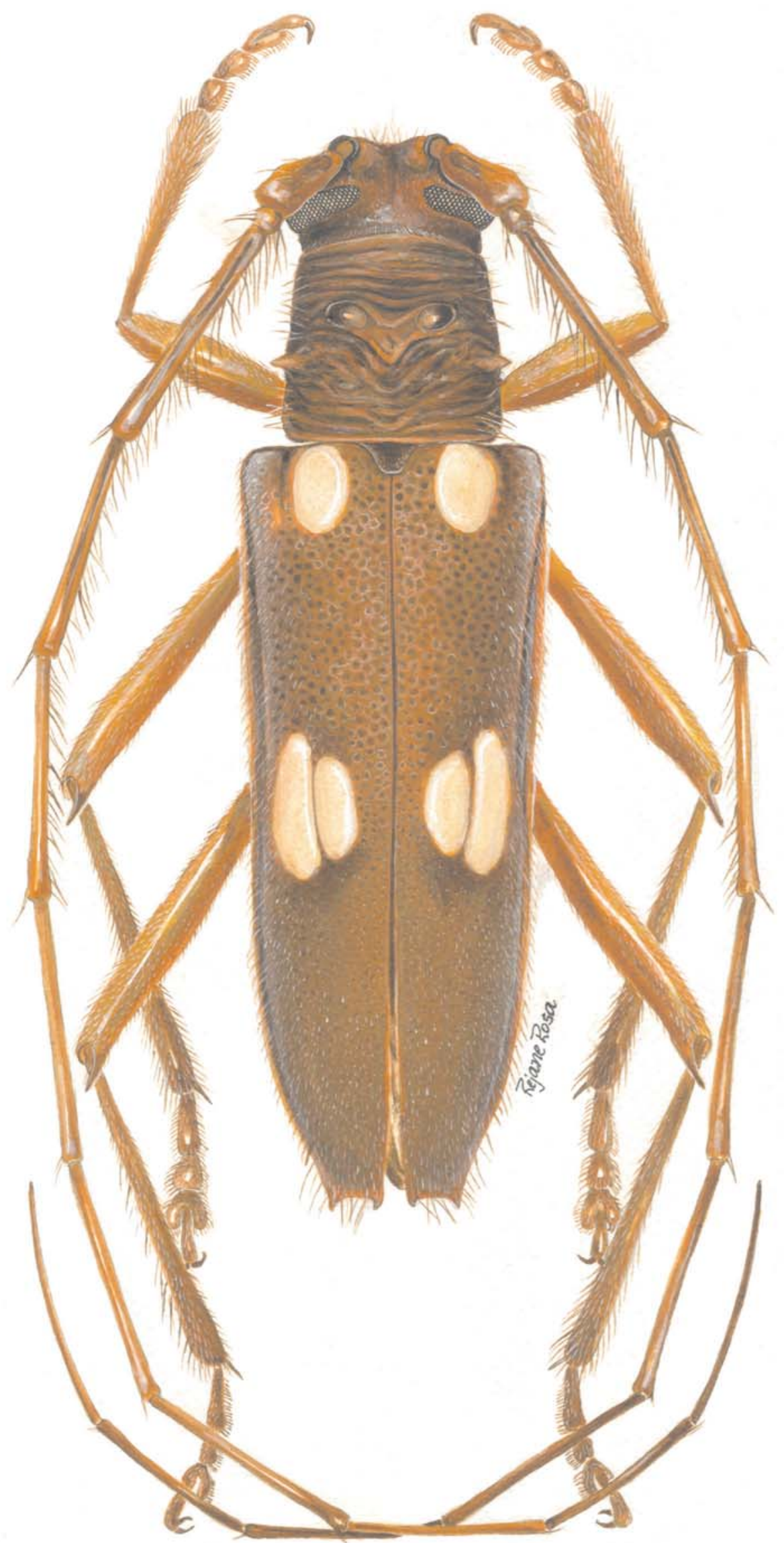

Fig. 2. Eburodacrys silviamariae sp. nov., holótipo ơ, comprimento $18,1 \mathrm{~mm}$.

Iheringia, Sér. Zool., Porto Alegre, 96(2):179-184, 30 de junho de 2006 
Dimensões (mm), holótipo . Comprimento total, 18,1; comprimento do protórax, 3,7; maior largura do protórax, 3,9; comprimento do élitro, 12,4; largura umeral, 4,3.

Material-tipo. Holótipo $\&$, sem etiqueta de procedência (USNM, etiqueta de acesso à coleção: "Tippmann collection 57 $213112 ")$.

Discussão. Uma espécie de reconhecimento muito fácil, embora não tenha procedência. Eburodacrys aenigma sp. nov. caracteriza-se pela faixa ebúrnea lateral dos élitros do terço basal ao meio (afastada da margem). Além disso, só há duas espécies no gênero com flagelômeros pretos e mesosterno com tubérculo (item 5 na chave para as espécies sul-americanas de MARTINS, 1999): E. lanei Zajciw, 1958 e E. bilineata Joly, 1992, que têm as faixas ebúrneas externas contínuas e as faixas internas ou também contínuas ou interrompidas logo atrás da base (MARTINS, 1999: figs. 153, 154, item 5 da chave). Em E. aenigma sp. nov., além da faixa lateral, contam-se quatro faixas dorsais em cada élitro (Fig. 3).

\section{Eburodacrys putia sp. nov. (Fig. 4)}

Etimologia. Tupi, putiá = tórax; alusivo às manchas pretas no pronoto.

Colorido geral alaranjado. Cabeça com mancha preta difusa atrás dos lobos oculares superiores. Antenas dos machos atingem a extremidade dos élitros aproximadamente na extremidade do antenômero VI. Escapo alongado, pouco e gradualmente espessado para o ápice; sem sulco nem dente interno na base. Protórax com tubérculo látero-anterior preto e espinho lateral

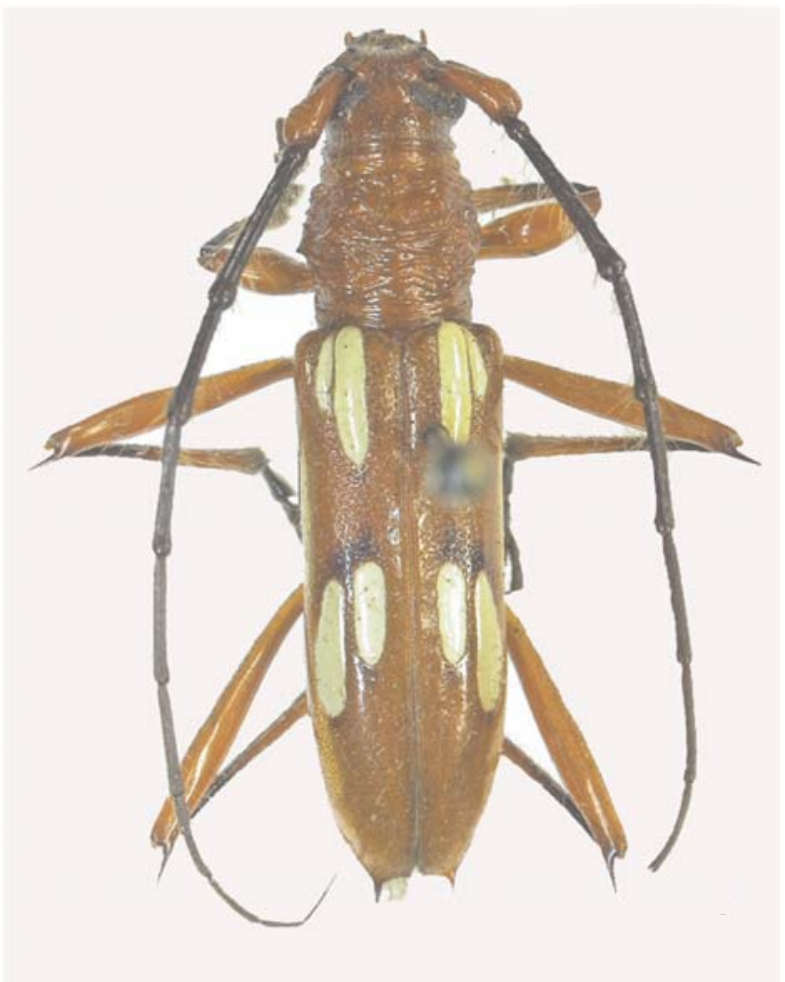

Fig.3. Eburodacrys aenigma sp. nov., holótipo \&, comprimento $18,1 \mathrm{~mm}$. concolor. Pronoto com tubérculos látero-anteriores pretos, brilhantes sobre mancha subcircular preta; duas manchas subcirculares pretas, na metade posterior; superfície do meio do pronoto com rugas irregulares e nos lados com rugas entremeadas por pontos. Mesosterno sem tubérculo. Cada élitro com três manchas ebúrneas estreitas: uma alongada (da base ao quinto anterior), seguida por mancha preta; duas centrais, contíguas, a externa apenas ultrapassa a interna na frente e um pouco mais atrás; perímetro dessas manchas enegrecido; duas costas branco-amareladas visíveis, especialmente para trás das manchas centrais. Extremidades elitrais com espinho concolor no lado externo. Espinho dos ápices dos meso- e metafêmures pretos.

Dimensões (mm), holótipo đ. Comprimento total, 13,2; comprimento do protórax, 2,7; maior largura do protórax, 3,0; comprimento do élitro, 9,4; largura umeral, 3,3.

Material-tipo. Holótipo $\widehat{\sigma}$, BOLÍVIA, Santa Cruz: Buena Vista, 18-25.X.1992, E. Giesbert col. (MNKM).

Discussão. Eburodacrys putia sp. nov. também se assemelha a E. notula Gounelle, 1909. Difere por apresentar mancha preta difusa atrás dos lobos oculares; por ter duas manchas pretas nos lados da base do pronoto (além dos tubérculos pretos); pela presença de costas atrás das manchas centrais dos élitros; pelo escapo alongado, com sulco basal muito débil, e pela mancha preta sobre o tubérculo látero-anterior do protórax.

Para distinguir E. putia sp. nov. de E. silviamariae sp. nov., basta mencionar as manchas pretas no pronoto, os espinhos elitrais longos no lado externo, a presença de costas atrás das manchas centrais dos élitros e os espinhos femorais pretos.

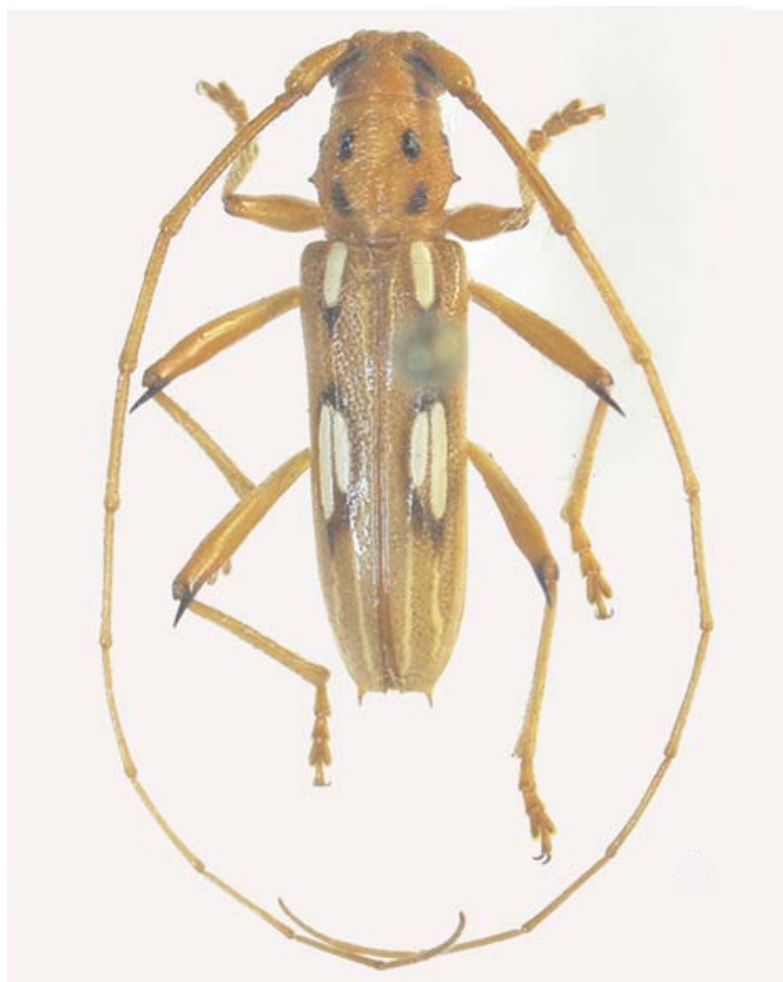

Fig. 4. Eburodacrys putia sp. nov., holótipo o, comprimento $13,2 \mathrm{~mm}$. 


\section{Eburodacrys ayri sp. nov.} (Fig. 5)

Etimologia. Tupi, ayrí, pequenino; alusivo ao seu pequeno tamanho.

Colorido geral alaranjado. Vértice com pontuação esparsa, rasa e irregular. Olhos grosseiramente facetados. Antenas dos machos atingem as extremidades elitrais aproximadamente na ponta do antenômero VIII. Escapo com sulco raso no lado dorsal da base. Antenômero III com sulco raso. Protórax com espinho lateral e tubérculo látero-anterior concolores. Pronoto com dois tubérculos desenvolvidos anteriores, o topo desses tubérculos indistintamente escurecido; superfície pronotal com poucas rugas e sem pontos. Mesosterno sem tubérculo. Cada élitro com três manchas ebúrneas: uma elíptica, convexa, na base, com escurecimento posterior discreto; duas contíguas, centrais, a externa inicia-se apenas atrás da interna e ultrapassa-a posteriormente em pequena extensão; regiões anterior e posterior das manchas indistintamente mais escurecidas. Extremidades elitrais com espinho externo curto e concolor. Espinhos femorais concolores.

Dimensões (mm), holótipo §. Comprimento total, 10,0; comprimento do protórax, 2,2; maior largura do protórax, 2,4; comprimento do élitro, 6,9; largura umeral, 2,6 .

Material-tipo. Holótipo ơ, COLÔMBIA, Rio Magdalena, Coleção Tippmann, sem outros dados (USNM). Como o Rio Magdalena atravessa diversas províncias, a localidade-tipo é bastante vaga.

Discussão. O aspecto geral de Eburodacrys ayri sp. nov. lembra muito o das espécies do gênero Pronuba Thomson, 1860, possibilidade que chegamos a aventar principalmente pela presença das duas espécies no sul da América Central, P. incognita Hovore \& Giesbert, 1990 e P. gracilis Hovore \& Giesbert, 1990. Entretanto, E. ayri sp. nov. tem caracteres que determinam seu posicionamento em Eburodacrys: olhos grosseiramente granulados com lobos inferiores grandes; escapo sulcado na base e lados do protórax com tubérculo látero-anterior. Em Pronuba, os olhos são finamente facetados com lobos inferiores curtos e tão longos quanto as genas; o escapo não tem sulco na base e o protórax não possui tubérculo látero-anterior.

Dentre as espécies de Eburodacrys, E. ayri sp. nov. assemelha-se a E. laevicornis Bates, 1884, do Panamá, Colômbia e Venezuela, mas separa-se pelos tubérculos pronotais concolores; pelas dimensões menores (comprimento $=10,0 \mathrm{~mm}$ ); pelo sulco raso no antenômero III e pelo pronoto quase sem escultura.

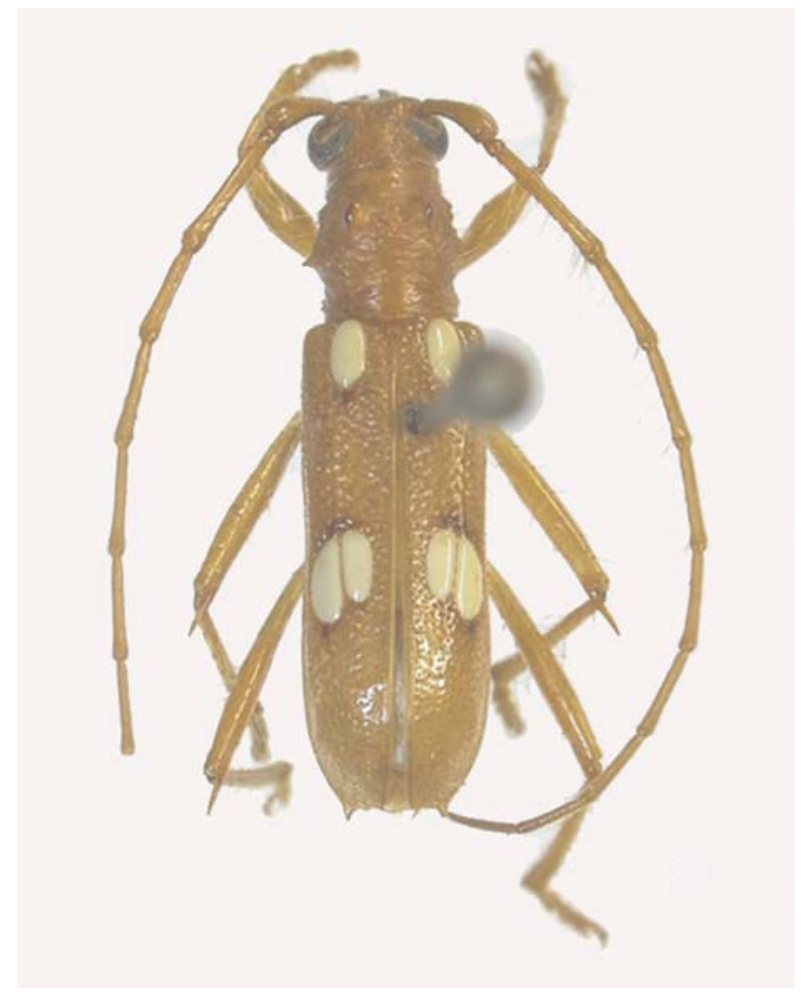

Fig. 5. Eburodacrys ayri sp. nov., holótipo o', comprimento 10,0 $\mathrm{mm}$.

Agradecimentos. A James E. Wappes (ACMB), pelo envio de material para estudo; a Rejane Rosa, pela execução das ilustrações e Rafael Santos de Araujo, pela arte fotográfica, ambos do Museu de Ciências Naturais, Fundação Zoobotânica do Rio Grande do Sul.

\section{REFERÊNCIAS BIBLIOGRÁFICAS}

Galileo, M. H. M. \& Martins, U. R. 2004. Novas espécies e nota sobre Cerambycidae (Coleoptera) neotropicais da coleção Arriagada, Santiago, Chile. Revista Brasileira de Entomologia 48(3):325-330.

Gounelle, E. 1909. Liste des cérambycides de la région de Jatahy. État de Goyaz, Brésil. Annales de la Societé Entomologique de France 77:587-688.

Martins, U. R. 1997. Contribuições para uma revisão das espécies sul-americanas da tribo Eburiini (Coleoptera, Cerambycidae). Revista Brasileira de Entomologia 41(1): 57-83.

_-_ org. 1999. Cerambycidae sul-americanos (Coleoptera). São Paulo, Sociedade Brasileira de Entomologia, v. 3, 418p.

Martins, U. R. \& Galileo, M. H. M. 2002. Cerambycidae (Coleoptera) da Colômbia. I. Eburiini (Cerambycinae). Iheringia, Sér. Zoologia, 92(4):5-10.

2005a. Cerambycidae (Coleoptera) da Colômbia. VII. Novos táxons, novos registros, nova sinonímia, nova combinação e novo nome. Revista Brasileira de Zoologia 22(1):5-18

2005b. Novos táxons e notas sobre Cerambycinae (Coleoptera, Cerambycidae) da Região Neotropical. Revista Brasileira de Zoologia 22(3):764-770.

Monné, M. A. 2005. Catalogue of the Cerambycidae (Coleoptera) of the Neotropical Region. Part I. Cerambycinae. Zootaxa 946: $1-765$.

Recebido em fevereiro de 2006. Aceito em maio de 2006. ISSN 0073-4721

Artigo disponível em: www.scielo.br/isz 